\title{
Klasifikasi Algoritma Iterative Dichotomizer (ID3) untuk Tingkat kepuasan pada Sarana Laboratorium Komputer
}

\author{
Ibnu Rasyid Munthe ${ }^{1}$, Volvo Sihombing ${ }^{2}$
}

Address: AMIK Labuhan Batu, Program Studi, Manajemen Informatika Indonesia ${ }^{1}{ }^{2}$

Email: ibnurasyidmunthe@gmail.com ${ }^{1}$, volvo_lecture@yahoo.co.id ${ }^{2}$

\begin{abstract}
Abstrak
Hasil Penelitian ini dilakukan membangun model menggunakan Algoritma Iterative Dichotomizer(Id3). Dengan mengukur Gain Ratio, Information Gain, Gini Index dan Akurasi maka hasil diperoleh Gain tertinggi dari Gain Ratio, Information Gain dan Gini Index adalah variabel Minat berkunjung kembali dan Entropy variabel Laboratorium Komputer artinya mahasiswa mau berkunjung kembali dan mengunakan Laboratorium komputer merasakan puas pada variabel tersebut. Accuracy gain tertinggi adalah variabel minat berkunjung kembali, entropy variabel Fasilitas penunjang, dan Laboratorium Komputer artinya mahasiswa berkunjung kembali dengan Fasilitas Penunjang Cukup dan perlu di tingkatan dan laboratorium komputer merasakan Puas. Data yang diolah menggunakan rapidminer dengan persentase 73,8 \% menyatakan Puas sebanyak 31 orang dan persentase $26,2 \%$ menyatakan tidak Puas sebanyak 11 orang dari total 42 orang. Metode yang digunakan menggali informasi Cross Industry Prosess For Data Mining (CRISP-DM). Mengukur nilai akurasi digunakan confusion matrik dengan klasifikasi nilai akurasi 0,95-1,00 sangat baik. Pengujian Data dilakukan dengan menggunakan aplikasi rapidminer.

Kata Kunci : Algoritma Iterative Dichotomizer(Id3), Gain Ratio, Information Gain, CRISP-DM, Confusion Matrik.
\end{abstract}

Keywords - : Algoritma Iterative Dichotomizer(Id3), Gain Ratio, Information Gain, CRISP-DM, Confusion Matrik

\begin{abstract}
The results of this study were carried out to build a model using the Iterative Dichotomizer Algorithm (Id3). By measuring Gain Ratio, Information Gain, Gini Index and Accuracy, the results are obtained by the highest gain of Gain Ratio, Information Gain and Gini Index are the variables of interest in revisiting and Entropy variables of the Computer Laboratory, meaning students want to visit again and use the Computer Laboratory to feel satisfied with these variables. The highest accuracy gain is a variable interest in visiting again, variable entropy of supporting facilities, and a computer laboratory means that students visit again with sufficient supporting facilities and need at the computer level and laboratory to feel satisfied. Data processed using rapidminer with a percentage of $73.8 \%$ stated satisfied as many as 31 people and the percentage of $26.2 \%$ said it was not satisfied as many as 11 people out of a total of 42 people. The method used to explore information is Cross Industry Process For Data Mining (CRISP-DM). Measuring the accuracy value is used matrix confusion with a classification value of $0.95-1.00$ accuracy is very good. Data testing is done using the Rapidminer application.
\end{abstract}

Keywords - : Iterative Dichotomizer Algorithm (Id3), Gain Ratio, Information Gain, CRISP-DM, Confusion Matrix

\section{Latar Belakang}

Mahasiswa merupakan konsumen (Pengguna) suatu insitusi pendidikan tinggi, maka Seorang mahasiswa, jika merasa puas dengan nilai yang diberikan oleh sarana laboratorium (produk komputer) dan fasilitas penunjang laboratorium tersebut, sangat besar kemungkinannya mahasiswa tersebut merekomendasikan kepada lingkungannya untuk memilih kampus yang baik dalam 
penyediaan sarana menjadi sebuah promosi alami untuk meningkatkan mahasiswa baru yang akan masuk pada kampus tersebut. Untuk melihat tingkat kepuasan baik produk dan jasa dalam penilaian mengenai produk atau jasa, maka dilihat seberapa jauh tingkat kesenangan konsumen berkaitan dengan pemenuhan kebutuhan konsumen terhadap produk dan jasa yang dikonsumsi.

Kepuasan merupakan penilaian mengenai ciri atau keistimewaan produk atau jasa, atau produk itu sendiri, yang menyediakan tingkat kesenangan konsumen berkaitandengan pemenuhan kebutuhan konsumsi konsumen[1]. Salah satu pendekatan untuk penemuan aturan adalah menggunakan Algortima Iterative Dichotomizer (ID3) untuk membuat pohon keputusan sehingga dapat digali pengetahuan dari permasalah yang terjadi.

Algoritma Iterative Dichotomiser 3 (ID3) merupakan sebuah metode yang digunakan untuk membangkitkan pohon keputusan[2]. untuk menggali informasi pada data mining dengan mengklasifikasikan dengan Algortima Iterative Dichotomizer (ID3). Pohon keputusan atau Decision tree merupakan salah satu metode mengklasifikasikan data pada data mining yang popular digunakan karena mudah diinterprestasikan oleh manusia dengan konsep dasar mengubah data menjadi pohon keputusan dan aturan-aturan keputusan[3]. Dalam penelitian ini fokus pada Klasifikasi Algoritma Iterative Dichotomizer(Id3) Untuk Tingkat Kepuasan Pada Sarana Laboratorium Komputer.

\section{Metode}

2.1. Klasifikasi mengunakan Algortima Iterative Dichotomizer (ID3).

Decision Tree salah satu metode klasifikasi dan prediksi yang sangat kuat dan terkenal, Decision tree merupakan salah satu metode klasifikasi yang menggunakan representasi struktur pohon (tree) di mana setiap node merepresentasikan atribut, cabangnya merepresentasikan nilai dari atribut, dan daun merepresentasikan kelas [4]. Adapun bagian-bagian dari Algoritma Iterative Dichotomiser (ID3) antara lain :

1. Induksi Decision Tree (ID3)

a) Dimulai dengan node akar

b) Untuk semua fitur, dihitung nilai entropy untuk semua sampel (data latih) pada node

c) Pilih fitur dengan informasi gain maksimal

d) Gunakan fitur tersebut sebagai node pemecahan menjadi cabang

e) Lakukan secara rekursif pada setiap cabang yang dibuat dengan mengulangi langkah 2 sampai 4 hingga semua data dalam setiap node hanya memberikan satu label kelas. Node yang tidak dapat dipecah lagi merupakan daun yang berisi keputusan(label kelas)

\section{Entropy}

Entropy adalah formula untuk menghitung homogenitas dari sebuah sample/contoh

$$
\begin{aligned}
& \text { Entropy }(\mathrm{S})=\sum_{i=1}^{c}-p_{1} \log _{2} p_{i} \\
& p_{i}=\frac{\mathrm{Zi}}{\mathrm{N}} \\
& Z_{\mathrm{i}}=\text { contoh positif + contoh negatif } \\
& \mathrm{N}=\text { jumlah data }
\end{aligned}
$$

\section{Gambar1. Rumus Entropy}

Keterangan

a. $\operatorname{Entropy}(\mathrm{S})=0$, jika semua contoh pada $\mathrm{S}$ berada dalam kelas yang sama.

b. Entropy $(S)=1$, jika jumlah contoh positif dan jumlah contoh negatif dalam $S$ adalah sama.

c. $0<\operatorname{Entropy}(S)<1$, jika jumlah contoh positif dan jumlah contoh negatif dalam $\mathrm{S}$ tidak sama.

3. Gain

Gain $(S, A)$ adalah Information Gain dari sebuah atribut $A$ pada contoh $S$ :

$$
\operatorname{Gain}(S, A)=\operatorname{Entropy}(S) \cdot \sum_{1 \in V \operatorname{dac}(\Lambda)} \frac{|S V|}{|S|} \operatorname{Entropy}\left(S_{V}\right)
$$

\section{Gambar 2. Rumus Gain}

\section{Pohon Keputusan (Decision Tree)}

Hasil dari perhitungan entopry dan gain maka dihasilkan pohon keputusan (Decision Tree). Konsep yang digunakan oleh decision tree untuk mengubah data menjadi suatu keputusan pohon dan aturan-aturan keputusan(rule)[7]. Contoh pohon keputusan (Decision Tree) Ramalan cuaca.

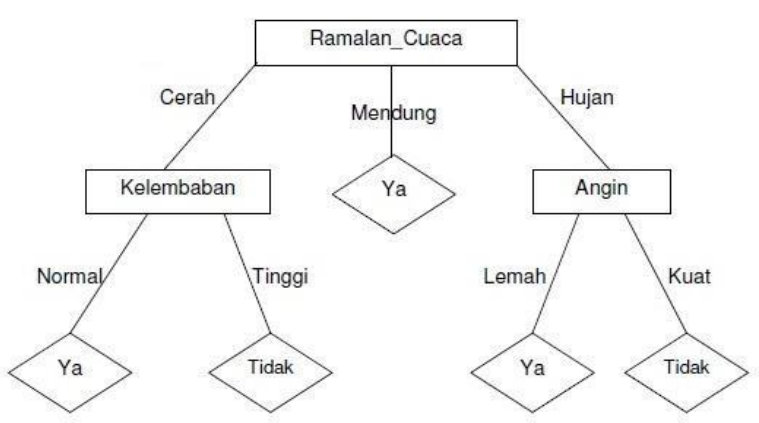

Gambar 3. Contoh Pohon Keputusan (Decision Tree) 5. Rule (Aturan) yang dihasilkan Hasil akhir dalam pengolahan data pada Algoritma Iterative Dichotomiser (ID3) pada contoh ramalan cuaca : IF Ramalan cuaca = Cerah maka AND Kelembaban = Tinggi THEN bermain tennis = Tidak

IF Ramalan cuaca $=$ Normal AND Kelembaban Normal THEN bermain tennis $=\mathrm{Ya}$

IF Ramalan cuaca $=$ Mendung THEN bermain tennis $=\mathrm{Ya}$ 
IF Ramalan cuaca $=$ Hujan AND Angin $=$ Kuat THEN bermain tennis $=$ Tidak

IF Ramalan cuaca $=$ Hujan AND Angin $=$ Lemah THEN

bermain tennis $=\mathrm{Ya}$

2.2. Cross Industry Prosess For Data Mining (CRISP-DM).

Tahapan-tahapan yang akan dilaksanakan sebagai

kerangka kerja penelitian. Setiap tahapan yang ada didasarkan pada metodelogi yang digunakan. Metode penelitian menggunakan Cross Industry Prosess For Data Mining (CRISP-DM)[8].

2.2.1. Pemahaman Penelitian (Business Understanding) Pada fase ini dalam proses CRISP-DM, Data

Understanding sebagai tahap pemahaman penelitian. Pada bagian ini dilakukan pemahaman mengenai tujuan dari kegiatan data mining yang akan dilakukan serta kebutuhan dari kegiatan tersebut. Dalam memahami data yang kemudian akan di analisa perlu mempelajari objek penelitian sebelumnya. Peneliti melihat berdasarkan latar belakang masalah yang terjadi maka diketahui kebutuhan mengenai data mining berasal dari AMIK Labuhan Batu. Bagaimana membuat pohon keputusan pada data kepuasan mahasiswa AMIK Labuhan Batu dengan metode Algortima Iterative Dichotomizer (ID3) di sarana laboratorium komputer.

Data pada tahapan ini mencakup semua kegiatan untuk mempersiapkan data yang akan dimasukkan ke dalam alat pemodelan, data tersebut diolah dari data mentah awal. Data yang diolah ke dalam ms.excel dengan menetapkan atribut (parameter telebih dahulu) dan kelas atau label dan mempelajari data tersebut sehingga harapan data tersebut memiliki pengetahuan yang lebih pada data yang diolah. Maka akan membantu dalam melakukan pemilihan data yang digunakan untuk proses data mining. Dalam melakukan data preparation yang perlu dilakukan ada beberapa tahapan dan akhirnya didaatkan data yang digunakan pada tahapan beikutnya, tahapan antara lain:
a) Data Sampling
b) Seleksi Data
c) Transformasi Data
d) Membersihkan data Cleaning Data

2.2.2. Pemahaman Data (Data Understanding)

Data Understanding atau pemahan data merupakan tahapan yang akan dilakukan pengumpulan terhadap data kemudian mempelajari data tersebut dengan tujuan untuk mengenal data, dan melakukan identifikasi dari data. Pada fase ini akan dibahas mengenai data yang akan digunakan untuk proses data mining.

\section{A. Pengumpulan Data}

Data yang digunakan data yang dikumpulkan dari AMIK Labuhan Batu melalui tahapan pemberian quisioner kepada mahasiswa AMIK Labuhan Batu. Kemudian data diolah dengan ms.excel dan dibaca langsung oleh aplikasi rapidminer disebabkan aplikasi tersebut mendukung format excel.

B. Penjelasan Data

Selanjutnya data yang telah dikumpukan, maka akan dilakukan pembelajaran (training) data yang digunakan dengan harapan dari pembelajaran (training) tersebut, data dapat dikenali lebih lanjut. Langkah ini bertujuan untuk membiasakan diri dengan data-data yang sudah dikumpukan dan berusaha menemukan waawasan mengenai informasi apa saja yang diperoleh. Dari hasil pengumpulan data, yang akan diketahui memiliki atributatribut sebagai berikut ini Atribut yang ada diambil dari indikator kepuasan pelanggan.

a) Kesesuaian Harapan

1. Kesesuaian Harapan pada fasilitas penunjang di laboratorium komputer.

2. Kesesuaian Harapan pada Komputer di laboratorium komputer

3. Minat Berkunjung kembali

Mahasiswa berminat berkunjung kembali untuk menggunakan fasilitas penunjang maupun komputer di laboratorium komputer.

b) Kelas atau Label

Kelas atau Label berupa kategorikal yang mengambarkan "Puas" dan Tidak Puas" terhadap objek Kesesuaian Harapan ( Fasilitas Penunjang, Komputer dan minat Berkunjung Kembali)

C. Atribut dari Variabel

1. Variabel Fasilitas Penunjang terdiri dari kategori Baik, Cukup, dan Kurang.

2. Variabel Komputer terdiri dari kategori Baik, Cukup, dan Kurnang

3. Variabel Minat Berkunjung Kembali terdiri kategori Berkunjung, dan Tidak Berkunjung

D. Identifikasi Data

Untuk melakukan identifikasi, dilakukan pemeriksaan mengenai kualitas dan kelengkapan pada data tersebut. Identifikasi meliputi nilai-nilai yang hilang atau kosong.

\subsubsection{Pengolahan Data (Data Preperation)}

Data pada tahapan ini mencakup semua kegiatan untuk mempersiapkan data yang akan dimasukkan ke dalam alat pemodelan, data tersebut diolah dari data mentah awal. Data yang diolah ke dalam ms.excel dengan menetapkan atribut (parameter telebih dahulu) dan kelas atau label dan mempelajari data tersebut sehingga harapan data tersebut memiliki pengetahuan yang lebih pada data yang diolah. Maka akan membantu dalam melakukan pemilihan data yang digunakan untuk proses data mining. Dalam melakukan data preparation yang perlu dilakukan ada beberapa tahapan dan akhirnya didapatkan data yang digunakan pada tahapan berikutnya, tahapan antara lain:
1. Data Sampling 
Data Sampling data yang akan digunakan untuk proses data mining pada tahapan selanjutnya. Data yang telah diolah ke ms.excel.

a) NPM, Nama Mahasiswa = Data Mahasiswa

b) Fasilitas Penunjang (Baik, Cukup, dan Kurang)

c) Laboratorium Komputer (Baik, Cukup, dan Kurang)

d) Minat berkunjung Kembali ( Berkunjung, dan Tidak Berkunjung)

e) Kepuasan Mahasiswa ( Puas dan Tidak Puas)

2. Seleksi Data

Data mentah yang diterima dari data kepuasan mahasiswa, selanjutnya dilakukan pemilihan terhadap parameter yang akan di analisis. Parameter yang diambil merupakan atribut yang sebelumnya telah dibuat dengan kelas atau label "puas" dan "tidak puas" atribut tersebut akan menjadi parameter atau variabel input Menjelaskan bawah Sampel adalah mahasiswa telah melakukan pengisian Quisioner tentang kepuasan mahasiswa AMIK Labuhan Batu pada sarana laboratorium komputer, atribut fasilitas penunjang adalah atribut dengan kategori fasilitas penunjang (Baik) apabila harapan telah dipenuhi, dan labelnya akan dijawab oleh mahasiswa apabila semua atribut dijawab dengan apakah mahasiswa merasakan "puas" atau “ tidak puas" pada fasilitas penunjang, laboratorium komputer, berminat berkunjung kembali.

3. Transformasi Data

Setelah data yang dipilih sudah ditetapkan maka tahapan selanjutnya melakukan transformasi terhadap parameter tertentu. untuk memudahkan proses perhitungan dengan mengunakan perhitungan Entropy, dan Gain untuk membuat pohon keputusan decision tree. Setiap atribut dikelompokan lagi misalnya Atribut fasilitas penunjang dengan kategori (baik) dan kelas kepuasan mahasiswa, Atribut fasilitas penunjang dengan kategori (cukup) dan kelas kepuasan mahasiswa dan Atribut fasilitas penunjang dengan kategori (kurang) dan kelas kepuasan mahasiswa.

4. Membersihkan Data

Tahap Cleaning dilakukan untuk proses pembersihan data agar data siap untuk tahapan modeling. Kegiatan ini membersihkan data yang hilang missing.

2.2.4. Model (Modeling)

Pada tahapan ini dilakukan proses pengolahan data mining dengan menggunakan algoritma Algoritma Iterative Dichotomiser (Id3) dilakukan dengan mengacu kepada bentuk data yang diinginkan atau dicapai dari penerapan data mining yaitu mengetahui pohon keputusan pada data kepuasan mahasiswa AMIK Labuhan Batu dengan metode Algortima Iterative Dichotomizer (ID3) di sarana laboratorium komputer. Metode yang digunakan dalam penelitian adalah Algortima Iterative Dichotomizer (ID3) untuk melakukan pengukuran akurasi dalam penelitian ini menggunakan perangkat lunak rapidminer. Berikut ini adalah gambaran proses Penelitian.

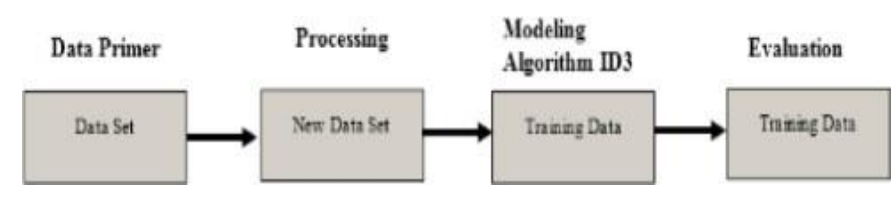

Gambar 4. Proses Penelitian yang digunakan

\subsubsection{Evaluasi(Evaluation)}

Tahapan evaluasi merupakan tahapan yang dilakukan untuk interprestasi terhadap hasil data mining yang telah dihasilkan pada tahapan sebelumnya.

3. Hasil

3.1. Data Set (Data Primer)

Data mentah yang diterima dari data kepuasan mahasiswa, selanjutnya dilakukan pemilihan terhadap parameter yang akan di analisis. Parameter yang diambil merupakan atribut yang sebelumnya telah dibuat dengan kelas atau label "puas" dan "tidak puas" atribut tersebut akan menjadi parameter atau variabel input. Data Kepuasan Mahasiswa Pada Laboratorium komputer AMIK Labuhan Batu menjelaskan bawah Data Primer adalah mahasiswa telah melakukan pengisian Quisioner tentang kepuasan mahasiswa AMIK Labuhan Batu pada sarana laboratorium komputer, atribut fasilitas penunjang adalah atribut dengan kategori fasilitas penunjang (Baik) apabila harapan telah dipenuhi, dan labelnya akan dijawab oleh mahasiswa apabila semua atribut dijawab dengan apakah mahasiswa merasakan "puas" atau "tidak puas" pada fasilitas penunjang, laboratorium komputer, berminat berkunjung kembali. Pada gambar dibawah ini Data yang di olah di rapidminer.

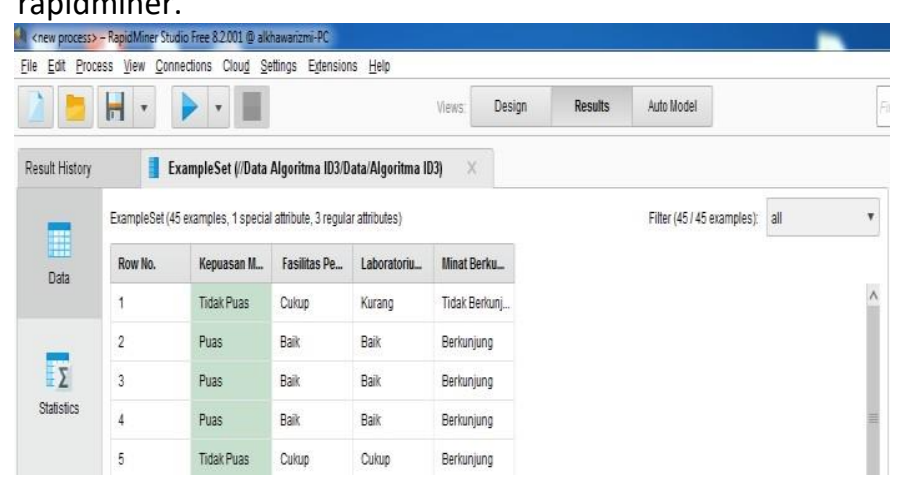

Gambar 5. Data diolah di Rapidminer.

Grafik Sebaran data kuiesioner yang telah diolah antara lain:

a) Kepuasan Mahasiswa Terhadap Fasilitas Penunjang 


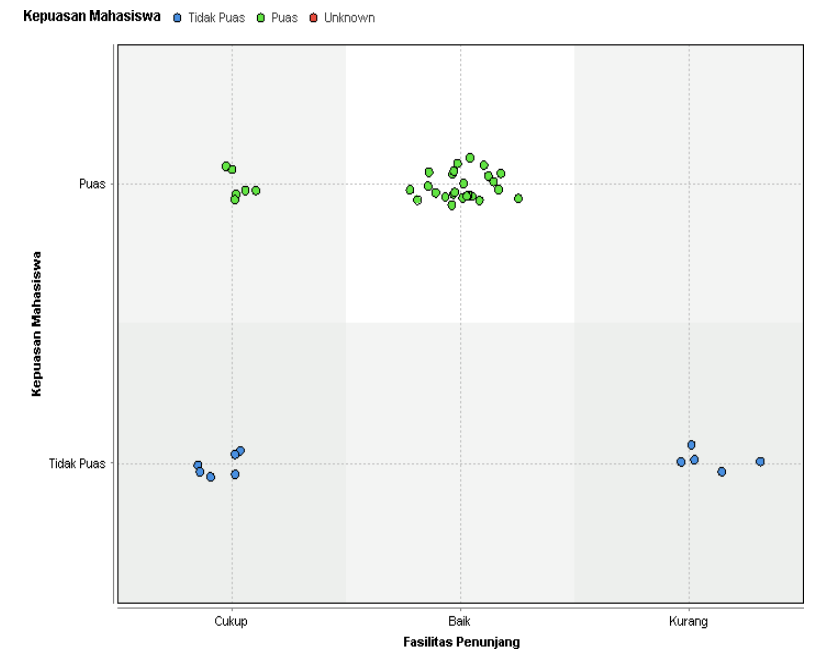

Gambar 6. Sebaran data kepuasan mahasiswa terhadap fasilitas penunjang

Pada Gambar 6 Grafik Kepuasan Mahasiswa dapat dilihat sebaran datanya dengan puas berwarna hijau dan tidak puas berwarna biru secara sebaran data tersebut lebih dominan tingkat kepuasan mahasiswa terhadap fasilitas penunjang.

b) Kepuasan Mahasiswa Terhadap Laboratorium Komputer

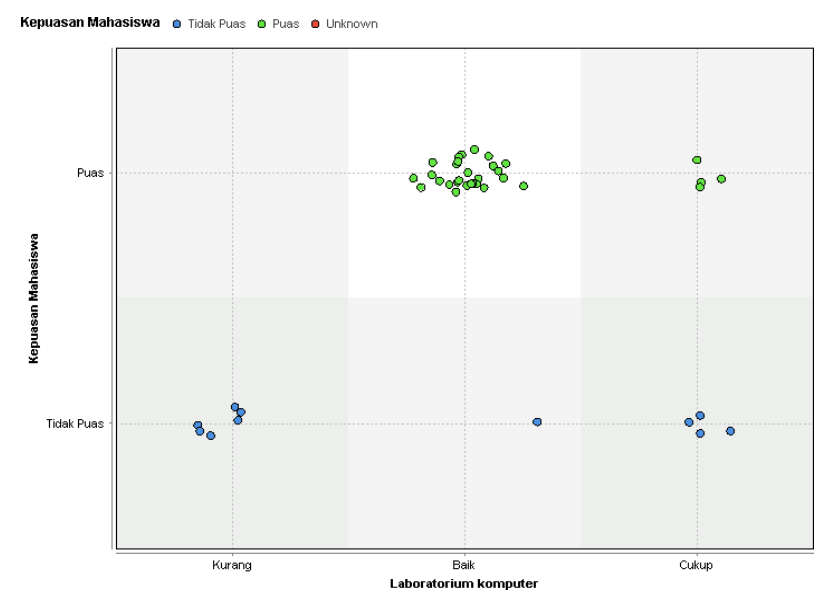

Gambar 7. Sebaran data kepuasan mahasiswa terhadap laboratorium computer

Pada gambar 7. Sebaran data kepuasan mahasiswa terhadap laboratorium dapat dilihat bahwa sebaran data mahasiswa menyatakan laboratorium baik dan puas lebih dominan.

c) Kepuasan Mahasiswa Terhadap minat untuk berkunjung kembali

Program Studi Teknik Informatika

Universitas Prima Indonesia (UNPRI) Medan

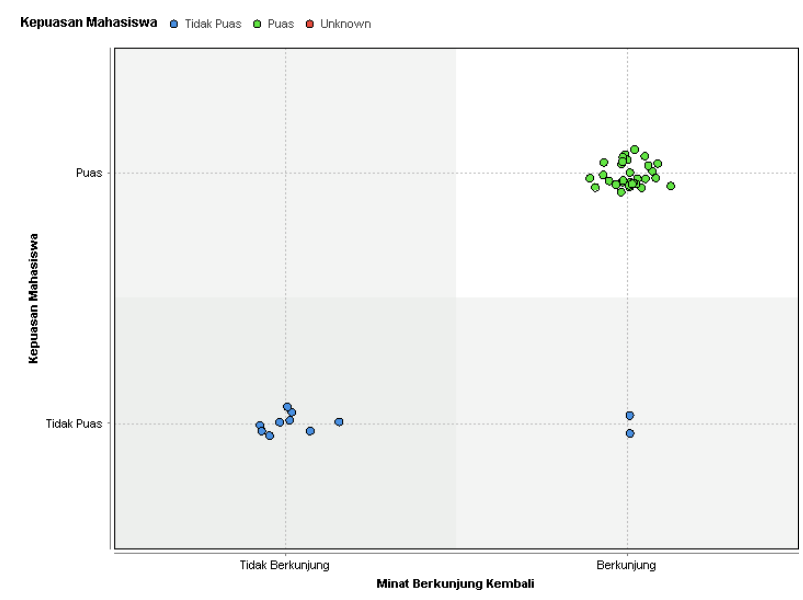

Gambar 8. Sebaran data kepuasan mahasiwa terhadap minat berkunjung kembali

Pada Gambar 8. Sebaran data kepuasan mahasiwa terhadap minat berkunjung kembali. Dapat dilihat bahwa sebaran data mahasiswa menyatakan ingin berkunjung kembali dan puas lebih dominan.

\subsection{Pengolahan Data (Processing)}

Pada gambar 9. Proses Pembersihan Data perangkat lunak rapid miner melakukan pengolahan data mulai dari rmembaca data primer kepuasan mahasiswa pada laboratorium komputer untuk memisahkan dengan memfilter data yang kosong missing value bertujuan agar pengolahan data pada tahap selanjutnya berjalan dengan baik. Cleaning data berfungsi sebagai data yang benar dan akan dipakai pada tahap selanjutya sedangkan Cleaning Data sebagai data yang missing dan tidak bisa melakukan pada tahap selanjutnya.

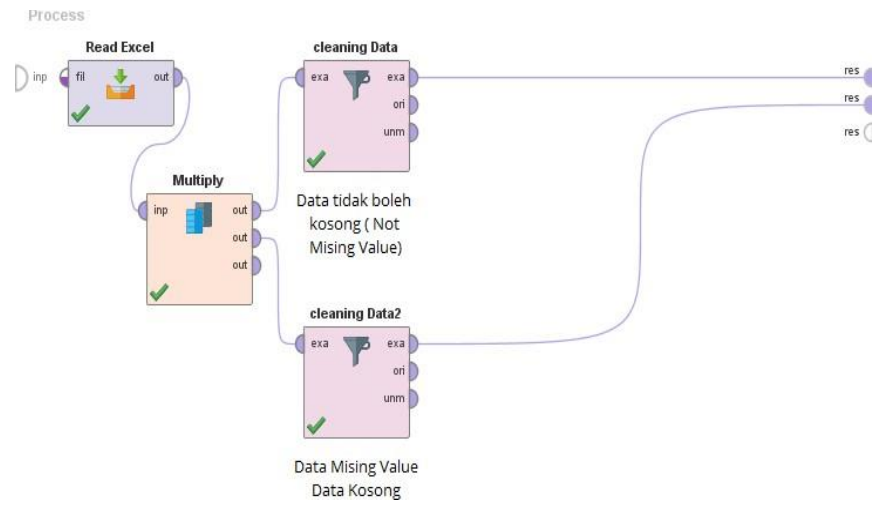

Gambar 9. Proses Pembersihan Data Perangkat Lunak Rapidminer

\subsection{Modeling}

Pada gambar 10. Pelatihan Data Algoritma ID3 adalah tahap membuat data pelatihan algoritma ID3 dengan melakukan pemodelan tersebut menghasilkan pohon keputusan tentang Data Kepuasan Mahasiswa pada 
Sarana Laboratorium Komputer. Dari hasil data pelatihan algoritma ID3 dapat pengetahuan.

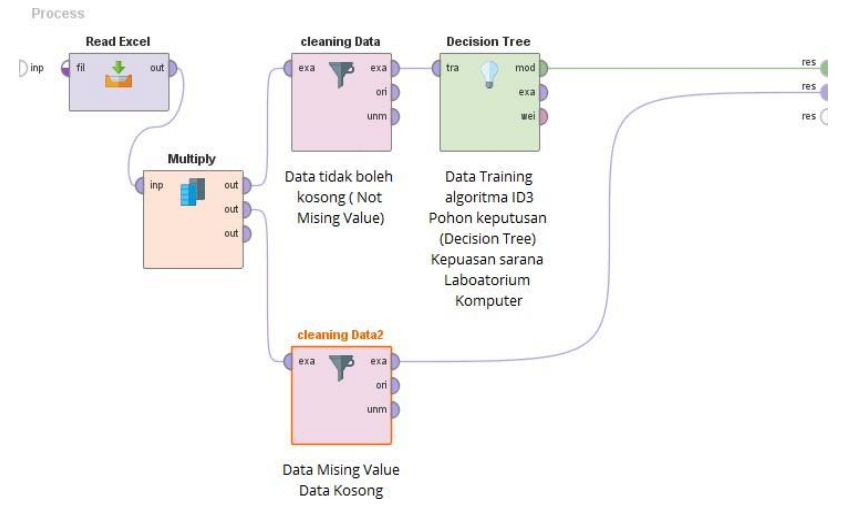

Gambar 10. Pelatihan Data Algoritma ID3

\subsection{Evaluasi}

Dari pengujian yang dilakukan terhadap data kepuasan mahasiswa pada sarana laboratorium melalui sebuah aplikasi rapidminer. Maka diperoleh sebuah hasil pohon keputusan (Decision Tree).

1. Gain Ratio Pohon Keputusan (Decision Tree ID3)

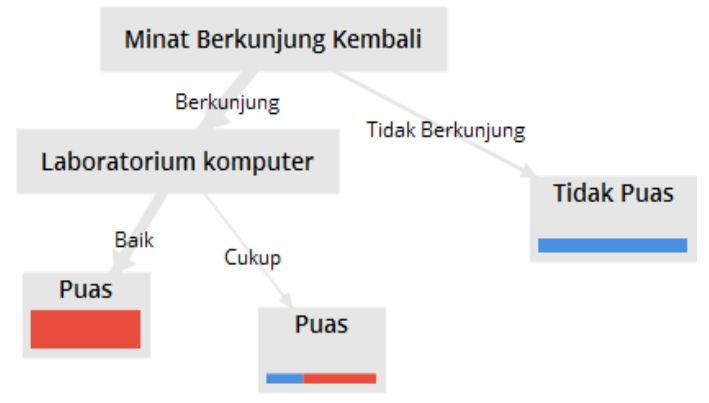

Gambar 11. Gain Ratio Pohon Keputusan ( Decision Tree ID3)

Gambar 11. Gain Ratio Pohon Keputusan (Decision Tree) menghasilkan Rule (aturan) tentang kepuasan pada sarana laboratorium komputer antara lain[9]:

a) IF Minat Berkunjung Kembali = Berkunjung Maka AND Laboratorium komputer = Baik Then Puas.

Data dari hasil quisioner yang menyatakan Puas sebanyak 27 orang

b) IF Minat Berkunjung Kembali = Berkunjung Maka AND Laboratorium Komuputer = Cukup Then Puas.

Data dari hasil quisioner yang menyatakan sebanyak 4 orang lebih dominan dari pada yang tidak Puas sebanyak 2 orang

c) IF Minat Berkunjung Kembali = Tidak Berkunjung Then Tidak Puas.

Program Studi Teknik Informatika

Universitas Prima Indonesia (UNPRI) Medan
Data dari hasil quisioner yang menyatakan tidak puas sebanyak 9 orang.

2. Information Gain Pohon Keputusan (Decision Tree ID3)

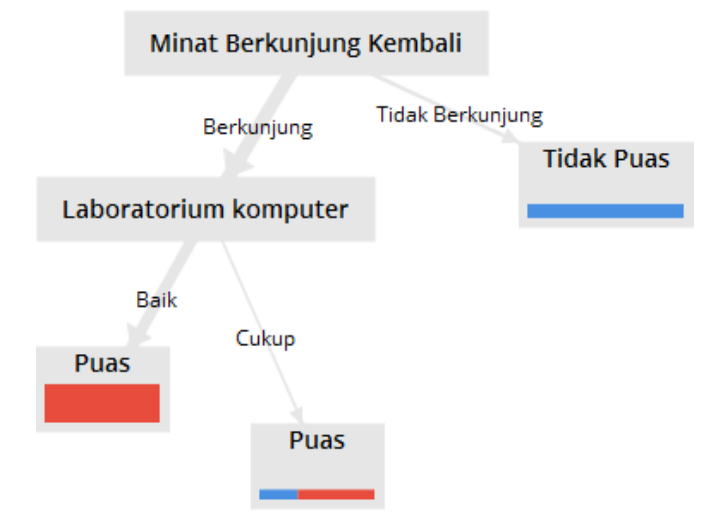

Gambar 12. Information Gain Pohon Keputusan (Decision Tree).

Gambar 12. Information Gain Pohon Keputusan (Decision Tree) menghasilkan Rule (aturan) tentang kepuasan pada sarana laboratorium komputer antara lain[10]:

a) IF Minat Berkunjung Kembali = Berkunjung Maka AND Laboratorium komputer = Baik Then Puas.

Data dari hasil quisioner yang menyatakan Puas sebanyak 27 orang

b) IF Minat Berkunjung Kembali = Berkunjung Maka AND Laboratorium Komuputer = Cukup Then Puas.

Data dari hasil quisioner yang menyatakan sebanyak 4 orang lebih dominan dari pada yang tidak Puas sebanyak 2 orang

c) IF Minat Berkunjung Kembali = Tidak Berkunjung Then Tidak Puas.

Data dari hasil quisioner yang menyatakan tidak puas sebanyak 9 orang.

3. Gini Index Pohon Keputusan (Decision Tree ID3)

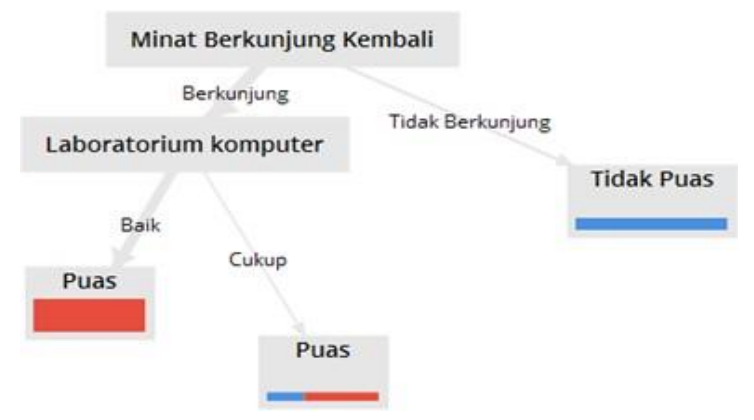

Gambar 13. Gini Index Pohon Keputusan (Decision Tree ID3) 
Gambar 13. Gini Index Pohon Keputusan (Decision Tree ID3) menghasilkan Rule (aturan) tentang kepuasan pada sarana laboratorium komputer antara lain:

a) IF Minat Berkunjung Kembali = Berkunjung Maka AND Laboratorium komputer $=$ Baik Then Puas. Data dari hasil quisioner yang menyatakan Puas sebanyak 27 orang

b) IF Minat Berkunjung Kembali = Berkunjung Maka AND Laboratorium Komuputer = Cukup Then Puas. Data dari hasil quisioner yang menyatakan sebanyak 4 orang lebih dominan dari pada yang tidak Puas sebanyak 2 orang

c) IF Minat Berkunjung Kembali = Tidak Berkunjung Then Tidak Puas.

Data dari hasil quisioner yang menyatakan tidak puas sebanyak 9 orang.

4. Accuracy Pohon Keputusan (Decision Tree ID3)

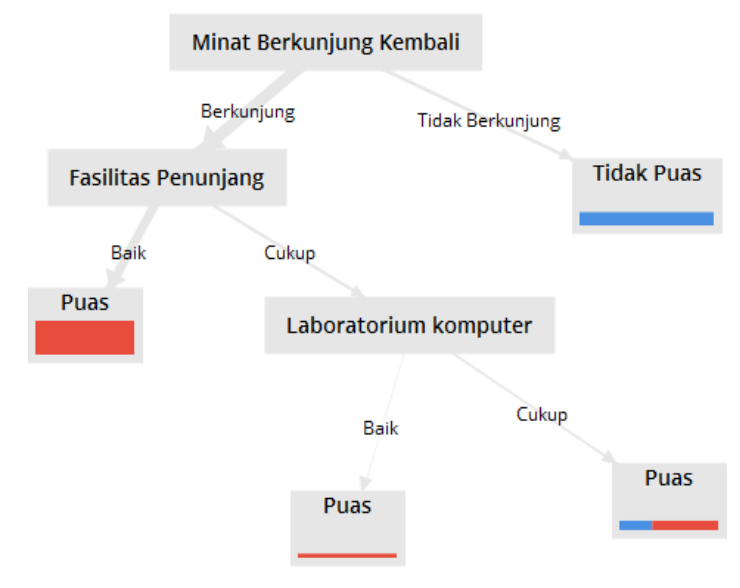

Gambar 14. Accuracy Pohon Keputusan (Decision Tree ID3)

Gambar 13. Gambar 14. Accuracy Pohon Keputusan (Decision Tree ID3) menghasilkan Rule (aturan) tentang kepuasan pada sarana laboratorium komputer antara lain:

a) IF Minat Berkunjung Kembali = Berkunjung maka AND Fasilitas Penunjang = Baik Then Puas

Data dari hasil quisioner yang menyatakan Puas sebanyak 25 orang

b) IF Minat Berkunjung Kembali = Berkunjung maka AND Fasilitas Penunjang = Baik maka AND Laboratorium = Baik Then Puas

Data dari hasil quisioner yang menyatakan Puas sebanyak 2 orang

c) IF Minat berkunjung kembali $=$ Berkunjung maka AND Fasilitas Penunjang = Cukup maka AND Laboratorium Komputer $=$ Cukup Then Puas Data dari hasil quisionet yang menyatakan puas sebanyak 4 orang lebih dominan dari pada tidak puas sebanyak 2 orang d) IF Minat Berkunjung Kembali = Tidak Berkunjung Then Tidak Puas sebanyak 9 orang.

\section{Kesimpulan}

Hasil Penelitian ini dilakukan membangun model menggunakan Algoritma Iterative Dichotomizer(Id3). Data Kepuasan Pada Sarana Laboratorium di AMIK Labuhan Batu Menghasilkan pohon keputusan.

a) Gain tertinggi baik dari Gain Ratio, Information Gain dan Gini Index adalah variabel Minat berkunjung kembali dan Entropy variabel Laboratorium Komputer artinya mahasiswa mau berkunjung kembali dan mengunakan Laboratorium komputer merasakan puas pada variabel tersebut

b) Accuracy gain tertinggi adalah variabel minat berkunjung kembali, entropy variabel Fasilitas penunjang, dan Laboratorium Komputer artinya mahasiswa berkunjung kembali dengan Fasilitas Penunjang Cukup dan perlu di tingkatkan dan laboratorium komputer merasakan Puas

c) Data yang diolah menggunakan rapidminer dengan persentase $73,8 \%$ menyatakan Puas sebanyak 31 orang dan persentase 26,2 \% menyatakan tidak Puas sebanyak 11 orang dari total 42 orang.

d) Mengukur nilai akurasi digunakan confusion matrik dengan klasifikasi nilai akurasi 0,95-1,00 sangat baik[11].

\section{Acknowledgement}

Peneliti mengucapkan Terimakasih kepada Direktorat Riset dan Pengabdian Masyarakat, dan Pendidikan Tinggi atas dukungan yang diberikan berupa bantuan dana penelitian yang menunjang berlangsungnya penelitian ini dengan baik. Melalui SKIM Penelitian Dosen Pemula Tahun Anggaran 2017.

\section{References}

[1] H. Al Rasyid, "Pengaruh Kualitas Layanan Dan Pemanfaatan Teknologi Terhadap Kepuasan Dan Loyalitas Pelanggan Go-Jek," J. Ecodemica, vol. 1 No. 2, no. 2, pp. 200-214, 2017.

[2] Y. Elmande and P. Widodo, "Pemilihan Criteria Splitting dalam Algoritma Iterative Dichotomiser 3 (ID3) untuk Penentuan Kualitas Beras: Studi Kasus Pada Perum Bulog Divre Lampung," J. Telemat. MKOM, vol. 4, no. 1, 2012.

[3] B. Hermanto, A. Sn, and F. P. Putra, "Analisis Kinerja Decision Tree C4.5 Dalam Prediksi Potensi Pelunasan Kredit Calon Debitur," Inovtek Polbeng Seri Inform., vol. 2, no. 2, 2017.

[4] Mochammad Yusa, E. Utami, and E. T. Luthfi, “Evaluasi Performa Algoritma Klasifikasi Decision 
Tree ID3 , C4,5 dan Cart pada Dataset Readmisi Pasien Diabetes," InfoSys J., vol. 4, no. 1, pp. 23-34, 2016.

[5] W. W. Ariestya, Y. E. Praptiningsih, and W. Supriatin, "Decision Tree Learning Untuk Penentuan Jalur Kelulusan Mahasiswa," J. IIm. FIFO, vol. 8, no. 1, p. 97, 2016.

[6] P. D. Nugraha, S. Al Faraby, and Adiwijaya, “Klasifikasi Dokumen Menggunakan Metode k Nearest Neighbor ( kNN ) dengan Information Gain Document Classification using k- Nearest Neighbor ( k NN ) Method with Information Gain," in eproceeding of engineering, 2018 , vol. 5, no. 1, pp. 114.

[7] M. Kusmira and R. E. Indrajit, "Penerapan Algoritma Klasifikasi Data Mining Decision Tree Untuk Menentukan Penjurusan Siswa SMA 6 Tasikmalaya," in Simposium Nasional IImu Pengetahuan dan
Teknologi (SIMNASIPTEK), 2017, pp. 49-53.

[8] I. R. Munthe, S. Sarkum, and V. Sihombing, "Analysis Iterative algorithms Dichotomizer (ID3 ): The Satisfaction Study in Computer Laboratory," in Proceedings of the Joint Workshop KO2PI and the 1st International Conference on Advance \& Scientific Innovation, 2018, pp. 178-184.

[9] F. Effendy and Purbandini, "Klasifikasi Rumah Tangga Miskin Menggunakan Ordinal Class Classifier," Teknol. dan Sist. Inf., vol. 04, no. 01, pp. 30-36, 2018.

[10] W. Maharani, "Klasifikasi Data Menggunakan JST Backpropagation Momentum Dengan Adaptive Learning Rate," Semin. Nas. Inform., vol. 1, no. semnasIF, pp. 25-31, 2009.

[11] M. A. A. K. Indrayanti, Devi Sugianti, "Peningkatan Akurasi Algoritma KNN dengan Seleksi Fitur G ain Ratio untuk Klasifikasi Penyakit Diabetes Mellitus," IC-Tech, vol. XII, no. 2, pp. 1-6, 2017. 